\title{
Papers
}

\section{Are seat belt restraints as effective in school age children as in adults? A prospective crash study}

\author{
Stephen I Halman, Mary Chipman, Patricia C Parkin, James G Wright
}

\begin{abstract}
Objective To study effectiveness of seat belts for protecting school age children in road vehicle crashes. Design Crash examinations by trained investigators. Setting Ten Canadian university based crash investigation centres.

Subjects 470 children aged 4-14 years, with 168 selected for detailed analysis, and 1301 adults.

Main outcomes measures Use of seat belts by vehicle occupants; severity of injury adjusted for age and crash severity.

Results Overall, 40\% (189/470) of children were unbelted. Of the 335 children in cars driven by belted adults, 73 (22\%) were unbelted. The odds of sustaining fatal or moderately severe injury (injury severity score $\geqslant 4$ ) for children in the front passenger seat was more than nine times higher for unbelted children than for belted ones (odds ratio 9.8 (95\% confidence interval 2.4 to 39.4)) and for those in the rear left seat was more than two times higher for unbelted than for belted children (2.6 (1.1 to 5.9)). The protection afforded by seat belts compared favourably with the results for adults in the same seat positions (odds ratios for unbelted $v$ belted adults of 2.4 and 2.7 for front and rear seat passengers respectively).

Conclusions Seat belts helped to protect school age children from injury in road vehicle crashes. However, $40 \%$ of children were unbelted. Despite standard seat belts being designed for adults, school age children were at least as well protected as adults.
\end{abstract}

\section{Introduction}

Road vehicle crashes are a leading cause of death in North America and the United Kingdom in children aged 4-14 years. ${ }^{12}$ In most developed countries traffic safety legislation mandates specific restraints for toddlers and infants, but there are no seat belts designed specifically for older children. School age children have to use the standard seat belts designed for adults.

Standard lap belts are designed to restrain an adult just below the centre of gravity at the pelvis. ${ }^{3}$ However, the immature anatomy of a child's pelvis cannot provide anchor points for the belt until the child is at least 10 years of age. ${ }^{4}$ Furthermore, the lap belt often rides up into the abdomen because children usually sit in a slouched posture. Thus, deceleration forces on children in the event of a crash may produce injuries in the abdomen and mid-lumbar spine, called the lap belt syndrome. ${ }^{5}{ }^{6}$ Although the addition of the torso sash to the lap belt should reduce the incidence of the lap belt syndrome, the torso sash transfers forces to the cervical spine. Because children's anatomy also makes them susceptible to cervical spine injuries, the lap-torso belt may place children at increased risk of cervical spine injuries. ${ }^{7}$

Research on the effectiveness of seat belts for school age children has provided mixed results. ${ }^{8-13}$ One study reported that lap belts reduced injuries to younger school age children but that lap-torso belts did not. ${ }^{12}$ Another study, using data from the National Highway Traffic Safety Association, reported that children were not as well protected as adults. ${ }^{10}$ The main limitations of these studies are that they lack detailed crash investigations, have no or only proxy measures of collision velocity ${ }^{10-12}$ rely on police reports for seat belt use $^{8}$ (which may be inaccurate ${ }^{14}$ ), and have potentially incomplete or inaccurate ascertainment of injury severity.

The purpose of our study was to determine whether seat belts are as effective for school age children as they are for adults.

\section{Methods}

\section{Selection of subjects}

The Road Safety and Motor Vehicle Regulation Directorate of Transport Canada funded a national network of 10 university based research teams, called the Passenger Car Study, to conduct in depth investigations of car crashes from 1984 to 1992 . Using a strategy similar to the fatality analysis reporting system of the US National Highway Traffic Safety Administration, ${ }^{15}$ each team in the Passenger Car Study investigated a sample of car crashes resulting in injury or death that occurred within a prescribed geographical area adjacent to the team's location. ${ }^{16}$ The Passenger Car Study used trained investigators to examine crash scenes for physical evidence. Seat belt use was determined primarily by examination of the interiors of the cars, including loading of the seat belt locking mechanism and seat belt fraying. The research teams had ethical approval for this study within their respective institutions.

We studied individual occupants identified in the Passenger Car Study who were aged 4-14 years; where,

\section{Division of Orthopaedic Surgery, Hospital for Sick Children 555 University Avenue, Toronto, Ontario, M5G 1X8, Canada Stephen I Halman research fellow James G Wright professor of surgery \\ University of \\ Toronto, Toronto, ON M5S 1A8 \\ Mary Chipman professor of public health sciences \\ Division of Pediatric Medicine, Hospital for Sick Children, Toronto \\ Patricia C Parkin associate professor of paediatrics \\ Correspondence to: J G Wright jim.wright@ sickkids.ca}

bmj.com 2002;324:1123 
Table 1 Comparison of seat belt status for 470 driver-child pairs involved in road vehicle crashes

\begin{tabular}{lrrr} 
& \multicolumn{3}{c}{ Children's seat belt status } \\
\cline { 2 - 4 } & Unbelted & Belted & Total \\
\hline Drivers' seat belt status: & & & \\
\hline Unbelted & 116 & 19 & 135 \\
\hline Belted & 73 & 262 & 335 \\
\hline Total & 189 & 281 & 470 \\
\hline
\end{tabular}

if seat belts were worn, they were worn correctly; and for whom complete data on their seat position and injury severity score were available. We excluded younger children because they are legally required to use child car seats and older children because we assumed they would be similar in size to adults. Fewer than $1 \%$ of the sample had used a booster seat or were involved in a crash where an airbag was deployed, and we therefore excluded these subjects.

\section{Outcome measures}

Collision investigators calculated the change in velocity experienced in the passenger compartment using the barrier equivalent velocity algorithm. Adjusting the analyses of the effectiveness of restraints for barrier equivalent velocity addresses the issue of different car safety features and the severity of a crash. ${ }^{17-19}$ Barrier equivalent velocity was available only in the later years of the study and, because of limited resources, was performed on only a single vehicle in each crash.

We obtained abbreviated injury scores from hospital and coroner documentation and used them to derive the Injury severity scores. ${ }^{20}{ }^{21}$ We decided a priori that a difference in mean injury severity score of $>1$ was clinically important. Because the injury severity score is not an interval scale, we also evaluated the score as a binary outcome response (score $\geqslant 4$ ) indicating at least moderately severe injury. ${ }^{2}$

\section{Statistical analysis}

In crashes with more than one child occupant, we randomly selected one school age child for analyses in order to preserve the independence of the observations. We performed analyses in two ways. Firstly, we performed a matched pair analysis comparing injury severity in adult drivers and child passengers. Secondly, because $90 \%$ of children wearing lap-torso belts were in the front passenger seat and $83 \%$ of the lap belt wearers were in either of the two rear outboard positions ( $\chi^{2}$ statistic $\mathrm{P}=0.01$ ), we also compared injury severity of adults with children in the front passenger seat to evaluate the effect of the lap-torso belt and in the rear left seat (behind the driver) to evaluate the effect of the lap belt.

Table 2 Characteristics of 168 child passengers involved in road vehicle crashes by seat position and seat belt status

\begin{tabular}{|c|c|c|c|c|c|c|}
\hline & \multicolumn{3}{|c|}{ Front right seat* } & \multicolumn{3}{|c|}{ Rear left seat† } \\
\hline & $\begin{array}{l}\text { Belted } \\
(n=56)\end{array}$ & $\begin{array}{l}\text { Unbelted } \\
(\mathrm{n}=27)\end{array}$ & $\begin{array}{l}\text { P value of } \\
\text { difference }\end{array}$ & $\begin{array}{l}\text { Belted } \\
(n=52)\end{array}$ & $\begin{array}{l}\text { Unbelted } \\
(\mathrm{n}=33)\end{array}$ & $\begin{array}{l}P \text { value of } \\
\text { difference }\end{array}$ \\
\hline Mean age (years) & 9.9 & 8.3 & 0.04 & 8.2 & 9.2 & 0.17 \\
\hline $\begin{array}{l}\text { Mean barrier equivalent } \\
\text { velocity }(\mathrm{km} / \mathrm{h})\end{array}$ & 28.7 & 30.8 & 0.62 & 30.2 & 31.7 & 0.73 \\
\hline Sex (\% male) & 55 & 56 & 0.7 & 50 & 42 & 0.5 \\
\hline
\end{tabular}

*Lap-torso type of seat belt. †Lap seat belt.

\section{Results}

The Passenger Car Study investigated 7853 crashes involving 13421 vehicles with 21629 occupants, of whom 796 were children aged 4-14 years with known seat belt status. Of the 796 children, 646 were in vehicles where occupants had correctly worn seat belts and had complete data for injury severity scores. We randomly selected one child from each car, yielding 470 children. Of these, only 23 children $(5 \%)$ were the sole injured occupant. Table 1 shows the seat belt status of the adult driver and child passenger for these cars. Overall, $40 \%$ of children and $29 \%$ of adults were unbelted. Among adult drivers who were belted, 22\% of the children in the same vehicle were unbelted (McNemar test; $\mathrm{P}=0.0001)$. Conditional logistic regression analysis showed that children were as well protected from moderately severe injury by wearing a seat belt as were the paired adult drivers (figure): compared with unbelted adults, the odds ratio of moderately severe injury for unbelted children was $0.76(95 \%$ confidence interval 0.36 to 1.6$)$, for belted adults 0.21 ( 0.058 to 0.77 ), and for belted children 0.12 (0.014 to 0.95$)$.

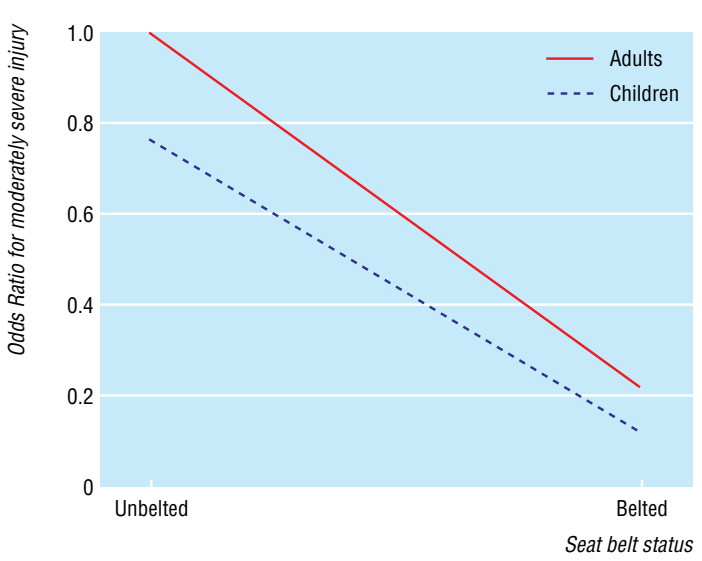

Conditional logistic regression of risk of moderately severe injury (injury severity score $\geqslant 4$ ) for 470 driver-child pairs involved in road vehicle crashes by seat belt status

From the 470 children, we selected a subset of 168 children (83 front seat and 85 rear seat) from later study years with complete information on barrier equivalent velocity for subsequent analyses (table 2). We compared these 168 children with 1301 adults (1144 front seat and 157 rear seat) with known seat belt status and complete injury severity scores. These analyses were stratified by front passenger seat and left rear seat.

Among the 83 children in the front passenger seat, $10(37 \%)$ of the 27 unbelted children were killed and $13(48 \%)$ sustained at least moderately severe injury (injury severity score $\geqslant 4$ ), compared with four $(7 \%)$ and nine $(16 \%)$ respectively of the 56 belted children (table 3). Among the 85 children in the rear left seat, five $(15 \%)$ of the 33 unbelted children were killed and $14(42 \%)$ were at least moderately severely injured, compared with six (12\%) and $13(25 \%)$ respectively of the 52 belted children (table 4 ). When these results are compared with those for 1144 adults in the front passenger seat (table 3) and 157 adults in the rear left seat 
Table 3 Comparison of injuries sustained by child and adult passengers involved in road vehicle crashes by seat belt status: front seat occupants

\begin{tabular}{lcc} 
& $\begin{array}{c}\text { Mean (95\% Cl) injury } \\
\text { severity score }\end{array}$ & $\begin{array}{c}\text { Odds ratio (95\% Cl) of } \\
\text { moderately severe injuryt }\end{array}$ \\
\hline Children $(n=83):$ & & \\
\hline Belted $(n=56)$ & $0.8(0.5$ to 1.2$)$ & 1.0 \\
\hline Unbelted $(n=27)$ & $3.4(2.0$ to 6.3$)$ & $9.8(2.4$ to 39.4$)$ \\
\hline Adults $(n=1144):$ & $1.7(1.5$ to 1.8$)$ & 1.0 \\
\hline Belted $(n=787)$ & $3.0(2.6$ to 3.6$)$ & $2.4(1.8$ to 3.2$)$ \\
\hline Unbelted $(n=357)$ & &
\end{tabular}

Table 4 Comparison of injuries sustained by child and adult passengers involved in road vehicle crashes by seat belt status: rear seat occupants

\begin{tabular}{lcc} 
& $\begin{array}{c}\text { Mean }(\mathbf{9 5 \%} \text { Cl) injury } \\
\text { severity score }{ }^{\star}\end{array}$ & $\begin{array}{c}\text { Odds ratio }(95 \% \text { Cl) of } \\
\text { moderately severe injuryt }\end{array}$ \\
\hline Children $(n=85):$ & \\
\hline Belted $(n=52)$ & $1.0(0.6$ to 1.6$)$ & 1.0 \\
\hline Unbelted $(n=53)$ & $2.1(1.2$ to 3.6$)$ & $2.6(1.1$ to 5.9$)$ \\
\hline Adults $(n=157):$ & & 1.0 \\
\hline Belted $(n=53)$ & $1.1(0.6$ to 1.7$)$ & $2.7(1.2$ to 6.2$)$ \\
\hline Unbelted $(n=104)$ & $2.2(1.6$ to 3.0$)$ &
\end{tabular}

*Adjusted for age and barrier equivalent velocity. †Injury severity score $\geqslant 4$.

(table 4), they show that seat belts were of similar or better effectiveness for the school age children.

\section{Discussion}

Our results consistently show that school age children involved in motor vehicle crashes were less severely injured if they were wearing a seat belt, irrespective of type of restraint (lap-torso or lap belt) or position in car (front passenger or rear left seat). In our study $40 \%$ of children were unbelted, placing them at significantly greater risk of injury. Distressingly, the use of restraints was higher in adults than children, and $22 \%$ of children travelling with belted drivers were themselves unbelted. A unique strength of our study is that the source of the data was from detailed crash inspections by trained investigators and injury severity was determined from hospital records.

Previous research has provided mixed results on the effectiveness of seat belts for school age children, and in some jurisdictions children are still allowed to travel unbelted in the back seats of road vehicles. ${ }^{15}$ The questions for health policy makers, and more immediately for parents, are whether restraints should be mandatory for children and what type of restraint is most appropriate. Although a standard lap belt may cause abdominal and spinal injuries in some children, the lap belt syndrome is rare (reported in one study to occur in only $1.4 \%$ of all child passengers injured in motor vehicle crashes $^{6}$ ). The slight possibility of this injury should not be misinterpreted by parents or clinicians to suggest that school age children should travel without a seat belt. Our study confirms the results of Corneli et $\mathrm{al}^{8}$ that school age children were at least as well protected as adults by standard seat belts. Therefore, the most critical issue identified in this study is the need to urge parents and guardians to "buckle up" their children.

Our findings do not answer the question about whether the degree of protection afforded by standard seat belts is sufficient. Firstly, parents may expect more protection for their children than they do for themselves. ${ }^{22}$ Secondly, we did not compare injury severity of the school age child with that of preschool children. Results from the National Highway Traffic and Safety Administration indicated that a child aged 5-14 years in a standard lap-torso belt had a risk of injury $70 \%$ higher than did a child aged $0-4$ years in a child car seat. ${ }^{10}$ Thus, although we found seat belts to be at least as effective for school age children as they were for adults, infants and toddlers may be even better protected in their respective restraints.

\section{Limitations of study}

The sampling for this study was not random, and the results may apply only to more severe crashes. The results are also conditional on the assumption that those with and without seat belt restraints are equally likely to be involved in crashes. Furthermore, this study, like all studies of injury, is subject to selection bias ${ }^{23} 24$ because subjects will be identified to police, ambulances, insurance companies, or tow truck drivers because of crash severity or injury. However, selection bias tends to reduce the estimated benefit of interventions, such as child restraint, because those who are protected are less likely to be identified. Thus, any such bias would lead to our underestimating the true protective effect of seat belts.

Another potential limitation of our study was that the reporting of seat belt use relied in part on occupants' self reports. However, a strength of this study was that, in contrast to prior studies, the assessment of seat belt use was based primarily on vehicle inspections by experienced collision investigators, including assessment of belt loading and fraying. Furthermore, any information from car occupants was obtained by an independent third party and in a confidential manner to maximise honest responses.

Our information on seat belt use was from 1984 to 1992, but a study in the mid-1990s reported similarly low rates of seat belt use, ${ }^{8}$ suggesting that use of child restraints has not substantially changed.

Finally, seat position and seat belt type were highly associated, making any inferences about their respective safety impossible.

\section{Conclusion}

School age children (4-14 years old) restrained with a seat belt were 2-10 times as safe as unbelted children in

\section{What is already known on this topic}

Although child restraints protect young children in road vehicle crashes, it is not known whether standard seat belts used by school age children work as well

School age children are often unbelted in cars What this study adds

Data from detailed crash assessments indicate that seat belts protected children at least as well as adults

Adults were more likely than children to be belted, and $22 \%$ of children travelling with belted drivers were unbelted 
car crashes and were at least as well protected as adults wearing seat belts. Despite these benefits, $40 \%$ of children in our study were unbelted. Urgent efforts should therefore be made to increase the use of seat belts by school age children. However, it is not clear if the degree of protection afforded by such belts could be improved. Given the impact of childhood injury on potential life lost, further research and development of highly effective restraints designed for school age children is warranted.

We thank Alan German, chief of Collision Investigation, Road Safety Department, Transport Canada, for his help with this study and providing the Passenger Car Study data.

Contributors: SIH and JGW wrote the paper. MC and PP helped design the study and commented on drafts. SH and MC performed the analyses. JW will act as guarantor for the paper.

Funding: JGW holds the Robert B Salter Chair in Paediatric Surgical Research and is a Canadian Institute of Health Research investigator. SIH was supported by the Research Training Centre of the Hospital for Sick Children.

Competing interests: None declared.

1 Pless B. Childhood injury prevention: time for tougher measures. Can Med Assoc J 1996;40:951-5.

2 National Highway Traffic Safety Administration. Third report to Congress: effectiveness of occupant protection systems and their use. Washington, DC: NHTSA, 1996.

3 Kelleher BJ, Walsh MJ, Dance DM, Gardner WT. An experimental study of the effects of child restraint improper installation and crash protection for larger size children. Warrendale, PA: Society of Automotive Engineers, 1983.

4 Johnson DL, Falci S. The diagnosis and treatment of pediatric lumbar spine injuries caused by rear seat lap belts. Neurosurgery 1990;26:434-41.

5 Glassman SD, Johnson JR, Holt RT. Seatbelt injuries in children. J Trauma 1992;33:882-6.

6 Lane JC. The seat belt syndrome in children. Accident Anal Prev 1994:26:813-20.
7 Hoy GA, Cole WG. The paediatric cervical seat belt syndrome. Injury 1993;24:297-9.

8 Corneli HM, Cook LJ, Dean JM. Adults and children in severe motor vehicle crashes: a matched-pairs study. Ann Emerg Med 2000;36:340-5.

9 Decker MD, Dewey MJ, Hutcheson RH, Schaffner W. The use and efficacy of child restraint devices-the Tennessee experience, 1982 and 1983. JAMA 1984;252:2571-5.

10 Johnston C, Rivara FP, Soderberg R. Children in car crashes: analysis of data for injury and use of restraints. Pediatrics 1994;93:960-5.

11 Osberg JS, Di Scala C. Morbidity among pediatric motor crash victims: the effectiveness of seat belts. Am J Public Health 1992;82:422-5.

12 Agran PF, Castillo DN, Winn DG. Comparison of motor vehicle occupant injuries in restrained and unrestrained 4- to 14-year olds. Accident Anal Preo 1992;24:349-55.

13 Berg MD, Cook L, Corneli HM, Vernon DD, Dean JM. Effect of seating position and restraint use on injuries to children in motor vehicle crashes. position and restraint use on
Pediatrics 2000;105:831-5.

14 Cooper PJ. Estimating over involvement of seat belt nonwearers in crashes and the effect of lap/shoulder restraint use on different crash severity consequences. Accident Anal Prev 1994;26:263-75.

15 Motor-vehicle occupant fatalities and restraint use among children aged 4-8 years-United States, 1994-1998. MMWR Morb Mortal Wkly Rep 2000;49:135-7.

16 Dalmotas DJ, German A, Hendrick BE, Hurley RM. Airbag deployments: the Canadian experience. J Trauma 1995;38:476-81.

17 Day TD, Hargens RL. An overview of the way ENDCRASH computes delta-v. Warrendale, PA: Society of Automotive Engineers, 1987.

18 Struble DE. Generalizing CRASH3 for reconstructing specific accidents. Warrendale, PA: Society of Automotive Engineers, 1987.

19 Tumbas NS, Smith RA. Measuring protocol for quantifying vehicle damage from an energy basis point of view. Warrendale, PA: Society of Automotive Engineers, 1988

20 Baker SP, O'Neill B, Haddon W, Long WB. The injury severity score: a method for describing patients with multiple injuries and evaluating emergency care. J Trauma 1974;14:187-96.

21 Linn S. The injury severity score-importance and uses. Ann Epidemiol 1995;5:440-6.

22 Eurenius K, Axelson O, Sjoden PO. Pregnancy, ultrasound screening and smoking attitudes. Gynecol Obstet Invest 1996;42:73-6.

23 Kleinbaum DG, Kupper LL, Morgenstern H. Epidemiologic research. New York: Van Nostrand Reinhold, 1982.

24 Waller JA. Methodologic issues in hospital-based injury research.J Trauma 1988;28:1632-6.

(Accepted 20 March 2002) 